\title{
A Comparison and Evaluation of Data Requirement Specification Techniques in SSADM and the Unified Process
}

\author{
Peter Bielkowicz and Thein T. Tun \\ Dept. of Computing, Information Systems and Mathematics \\ London Guildhall University \\ 100 Minories, London EC3N 1JY, UK \\ \{bielkowi, tthe08\}@lgu.ac.uk
}

\begin{abstract}
During the analysis stage of a typical information system development process, user requirements concerning system functionality and data are captured and specified using requirement specification techniques. Most of these specification techniques are graphical (semi-formal), i.e. they involve modelling. This paper presents a comparison of data requirement specification techniques in SSADM, which is a strong data-centred method, and the Unified Process, an object-oriented method. In particular, we investigated how data groups (entities and classes), their attributes and relationships are identified, specified and validated in both methods. Data requirement specification techniques used in both methods are then evaluated against a set of detailed criteria based on five requirement specification quality attributes. Both methods seem to have a similar informal approach to producing initial data requirement specifications, but they differ when these initial models are refined. The refinement in SSADM is more rigorous. Therefore, this paper makes a few recommendations for the Unified Process.
\end{abstract}

\section{Introduction}

This paper has the following structure. The quality attributes of a good data requirement specification and criteria for evaluation used in this paper are discussed in the next section. It is followed by a brief overview of data requirement specification techniques in SSADM and an assessment of them. A summary of data requirement specification techniques in the Unified Process and an assessment of them are to be found in the subsequent section. The last two sections are devoted to the summary of our findings and, conclusions and recommendations.

\section{Properties of a Good Data Requirements Specification}

Authors such as [6], [7], [8], [10] and [11] have discussed quality attributes that general requirements specifications should posses. Based on some of the common criteria considered by those authors and others, we propose a set of characteristics that are important to a data requirement specification. They are completeness, minimality, correctness, non-redundancy and consistency. These characteristics apply to different 
levels of comprehension of the user's requirements, namely, description level, semantic level, and contextual level.

\section{Description Level}

This is a superficial level at which one can check whether a data requirement specification contains all requirements wished by the user. Mere mentions of reasonably detailed requirements wanted by the user in the specification would satisfy the completeness of the specification.

1. Completeness - A data requirement specification is complete if the specification captures adequate information about the problem domain, i.e. the specification contains all elements desired by the user.

One will also have to make sure that the specification does not contain requirements that are not wanted by the user.

2. Minimality - A data specification is minimal if the specification does not contain elements that are not desired by the user.

The first characteristic necessitates that important data requirements are not missing in the specification. The second characteristic demands that the specification does not have any requirements from outside the problem domain. Combining the two characteristics, in effect, will amount to the (set of) requirements in the specification being roughly equal to the (set of) real user's requirements. However, it is not clear at this level whether the analyst's understanding of requirements is in line with the user's. Those misunderstandings can only be detected at a deeper semantic level.

\section{Semantic Level}

At this level, the analyst should strive to demonstrate that the semantics of the specification is the same as the user's real intentions.

3. Correctness - A data specification is correct if there are no differences in the user's understanding of the requirements specification and the semantics of the requirements specification itself.

By now, one should have a fairly reliable specification. To enforce a good structure onto the specification, one will need to remove superfluous requirements.

4. Non-redundancy - A data specification contains no redundant elements if no two elements represent the same information.

Non-redundancy characteristic will compel the requirement analyst to expose unnecessary overlaps in the specification. Please note that non-redundancy is a semantic level criterion, while minimality is a description level one, and see Table 1 for illustrations.

Finally, the data requirement specification should show consistency with other specification such as specification of system functionality.

\section{Contextual Level}

A data requirement specification will not exist in isolation. It will have to share information with other specifications. Therefore, it is important that requirements are defined consistently. 
5. Consistency - A data specification is consistent with other specifications if the specification does not present any conflicting requirements. Some authors such as [7] and [6] distinguish between two kinds of consistencies: internal consistency and external consistency. Internal consistency is the consistency of various elements within a specification or model and external consistency is the consistency of specifications of elements across various models. In the context of data requirement specification technique, the external consistency is more plausible than the internal one. Since consistency is applied to various specifications, it is a very important criterion. Without it, it will be very difficult to ensure that other criteria, namely, completeness, minimality, correctness and non-redundancy are met.

The five characteristics discussed above apply to various elements in the specification.

\section{Three Major Elements of Data Requirements and Their Characteristics}

What exactly do we mean by 'data requirements'? In the context of system development methodologies, data requirements include the following elements, or in other words, data requirements are described using the following notions/concepts:

- Data groups

- Data attributes and

- Relationships between data groups

A data group is a collection of data attributes, such as entities in Relational Data Models and classes in a Class Model. Data attributes are pieces of information such as attributes of entities, and properties/attributes of a class. Relationship between data groups means a static connection between the data groups such as entity relationships, and class relationships, e.g. association, aggregation.

In a 'good' data requirement specification, all three elements (notions/concepts) should possess all the characteristics described above, except consistency that is applicable to specifications as a whole only. It gives rise to thirteen detailed criteria that can be used for evaluation of data requirement specification techniques. These criteria with illustrative examples are summarised in Table 1 that uses a small student library system as a case study scenario.

\section{Implications for Methodologies}

In the light of the discussion so far, it seems natural to expect a meticulous data requirement specification technique to provide mechanisms to guarantee that data requirement specifications meet some or all of the above-mentioned criteria. In fact, there are two different but interrelated issues: first, the strength of the technique itself to deliver a specification that meets the criteria above; second, checking mechanisms to validate that the criteria have been met. But we will not generally attempt to separate the two issues in this paper; rather, we will focus on overall rigour of the entire technique(s) to produce a good data requirement specification. 
Table 1. Levels, characteristics, criteria and examples

\begin{tabular}{|c|c|c|c|c|c|}
\hline Level & $\begin{array}{l}\text { Character- } \\
\text { istic }\end{array}$ & Element & Criterion & Meaning & Example \\
\hline $\begin{array}{l}\text { Descrip- } \\
\text { tion }\end{array}$ & $\begin{array}{l}\text { Complete- } \\
\text { ness }\end{array}$ & $\begin{array}{l}\text { Data } \\
\text { groups }\end{array}$ & $\begin{array}{l}\text { Complete- } \\
\text { ness of } \\
\text { data } \\
\text { groups }\end{array}$ & $\begin{array}{l}\text { No missing } \\
\text { entity/class in } \\
\text { the } \\
\text { specification }\end{array}$ & $\begin{array}{l}\text { Reader class/entity } \\
\text { missing from the } \\
\text { library system }\end{array}$ \\
\hline $\begin{array}{l}\text { Descrip- } \\
\text { tion }\end{array}$ & $\begin{array}{l}\text { Complete- } \\
\text { ness }\end{array}$ & $\begin{array}{l}\text { Data } \\
\text { elements }\end{array}$ & $\begin{array}{l}\text { Complete- } \\
\text { ness of } \\
\text { data } \\
\text { elements }\end{array}$ & $\begin{array}{l}\text { No missing } \\
\text { attributes in } \\
\text { entities }\end{array}$ & $\begin{array}{l}\text { Reader name missing } \\
\text { from the Reader } \\
\text { entity/class }\end{array}$ \\
\hline $\begin{array}{l}\text { Descrip- } \\
\text { tion }\end{array}$ & $\begin{array}{l}\text { Complete- } \\
\text { ness }\end{array}$ & $\begin{array}{l}\text { Relation- } \\
\text { ships }\end{array}$ & $\begin{array}{l}\text { Complete- } \\
\text { ness of } \\
\text { relation- } \\
\text { ships }\end{array}$ & $\begin{array}{l}\text { No missing } \\
\text { relationships } \\
\text { in between } \\
\text { classes/ } \\
\text { entities }\end{array}$ & $\begin{array}{l}\text { Reader-Loan } \\
\text { relationship missing } \\
\text { between Reader and } \\
\text { Loan entity/class }\end{array}$ \\
\hline $\begin{array}{l}\text { Descrip- } \\
\text { tion }\end{array}$ & $\begin{array}{l}\text { Mini- } \\
\text { mality }\end{array}$ & $\begin{array}{l}\text { Data } \\
\text { groups }\end{array}$ & $\begin{array}{l}\text { Mini- } \\
\text { mality of } \\
\text { data } \\
\text { groups }\end{array}$ & $\begin{array}{l}\text { No extra } \\
\text { entity/class in } \\
\text { the } \\
\text { specification }\end{array}$ & $\begin{array}{l}\text { Publisher entity/class } \\
\text { (where it is not } \\
\text { deemed required) }\end{array}$ \\
\hline $\begin{array}{l}\text { Descrip- } \\
\text { tion }\end{array}$ & $\begin{array}{l}\text { Mini- } \\
\text { mality }\end{array}$ & $\begin{array}{l}\text { Data } \\
\text { elements }\end{array}$ & $\begin{array}{l}\text { Mini- } \\
\text { mality of } \\
\text { data } \\
\text { elements }\end{array}$ & $\begin{array}{l}\text { No extra } \\
\text { attributes in } \\
\text { classes/ } \\
\text { entities }\end{array}$ & $\begin{array}{l}\text { Reader's weight } \\
\text { attribute in Reader } \\
\text { entity }\end{array}$ \\
\hline $\begin{array}{l}\text { Descrip- } \\
\text { tion }\end{array}$ & $\begin{array}{l}\text { Mini- } \\
\text { mality }\end{array}$ & $\begin{array}{l}\text { Relation- } \\
\text { ships }\end{array}$ & $\begin{array}{l}\text { Mini- } \\
\text { mality of } \\
\text { relation- } \\
\text { ships }\end{array}$ & $\begin{array}{l}\text { No extra } \\
\text { relationships } \\
\text { between } \\
\text { entities/ } \\
\text { classes }\end{array}$ & $\begin{array}{l}\text { Relationship between } \\
\text { Book Title and } \\
\text { Publisher } \\
\text { entities/classes where } \\
\text { Publisher is not } \\
\text { required }\end{array}$ \\
\hline Semantic & $\begin{array}{l}\text { Correct- } \\
\text { ness }\end{array}$ & $\begin{array}{l}\text { Data } \\
\text { groups }\end{array}$ & $\begin{array}{l}\text { Correct- } \\
\text { ness of } \\
\text { data } \\
\text { groups }\end{array}$ & $\begin{array}{l}\text { No } \\
\text { entity/class } \\
\text { with invalid } \\
\text { meaning }\end{array}$ & $\begin{array}{l}\text { Assuming Reader the } \\
\text { same as Student } \\
\text { entity/class, when the } \\
\text { business rule is that } \\
\text { only those students } \\
\text { who have borrowed } \\
\text { at least one item is } \\
\text { considered as Reader }\end{array}$ \\
\hline Semantic & $\begin{array}{l}\text { Correct- } \\
\text { ness }\end{array}$ & $\begin{array}{l}\text { Data } \\
\text { elements }\end{array}$ & $\begin{array}{l}\text { Correct- } \\
\text { ness of } \\
\text { data } \\
\text { elements }\end{array}$ & $\begin{array}{l}\text { No attributes } \\
\text { with invalid } \\
\text { meaning in an } \\
\text { entity/class }\end{array}$ & $\begin{array}{l}\text { Assuming Address } \\
\text { attribute holds home } \\
\text { address when it } \\
\text { should be current } \\
\text { address }\end{array}$ \\
\hline Semantic & $\begin{array}{l}\text { Correct- } \\
\text { ness }\end{array}$ & $\begin{array}{l}\text { Relation- } \\
\text { ships }\end{array}$ & $\begin{array}{l}\text { Correct- } \\
\text { ness of } \\
\text { relation- } \\
\text { ships }\end{array}$ & $\begin{array}{l}\text { No } \\
\text { relationship } \\
\text { with invalid } \\
\text { meaning } \\
\text { between } \\
\text { entities/ } \\
\text { classes }\end{array}$ & $\begin{array}{l}\text { Wrong cardinalities } \\
\text { etc... }\end{array}$ \\
\hline
\end{tabular}




\begin{tabular}{|l|l|l|l|l|l|}
\hline Level & $\begin{array}{l}\text { Character- } \\
\text { istic }\end{array}$ & Element & Criterion & Meaning & Example \\
\hline Semantic & $\begin{array}{l}\text { Non- } \\
\text { cy }\end{array}$ & $\begin{array}{l}\text { Data } \\
\text { groups }\end{array}$ & $\begin{array}{l}\text { Non- } \\
\text { redun- } \\
\text { dancy of } \\
\text { data } \\
\text { groups }\end{array}$ & $\begin{array}{l}\text { No two } \\
\text { entities/ } \\
\text { classes with } \\
\text { the same } \\
\text { meaning in } \\
\text { the } \\
\text { specification }\end{array}$ & $\begin{array}{l}\text { Student and Reader } \\
\text { entities when they are } \\
\text { the same }\end{array}$ \\
\hline Semantic & $\begin{array}{l}\text { Non- } \\
\text { redundan- } \\
\text { cy }\end{array}$ & $\begin{array}{l}\text { Data } \\
\text { elements }\end{array}$ & $\begin{array}{l}\text { Non- } \\
\text { redun- } \\
\text { dancy of } \\
\text { data } \\
\text { elements }\end{array}$ & $\begin{array}{l}\text { No derivable } \\
\text { attributes and } \\
\text { attributes that } \\
\text { share same } \\
\text { information }\end{array}$ & $\begin{array}{l}\text { Having Date of Birth } \\
\text { and Age attributes, or } \\
\text { Address and Post } \\
\text { Code attributes when } \\
\text { Address also contains } \\
\text { Post Code }\end{array}$ \\
\hline Semantic & $\begin{array}{l}\text { Non- } \\
\text { redundan- } \\
\text { cy }\end{array}$ & $\begin{array}{l}\text { Relation- } \\
\text { ships }\end{array}$ & $\begin{array}{l}\text { Non- } \\
\text { redun- } \\
\text { dancy of } \\
\text { relation- } \\
\text { ships }\end{array}$ & $\begin{array}{l}\text { No } \\
\text { entity/class } \\
\text { relationships } \\
\text { which are to } \\
\text { provide } \\
\text { alternative } \\
\text { navigation } \\
\text { routes }\end{array}$ & $\begin{array}{l}\text { Circular relationships } \\
\text { between } \\
\text { entities/classes where } \\
\text { some of them are } \\
\text { solely for alternative } \\
\text { route for navigation }\end{array}$ \\
\hline $\begin{array}{l}\text { Contextu } \\
\text {-al }\end{array}$ & $\begin{array}{l}\text { Consis- } \\
\text { tency }\end{array}$ & $\begin{array}{l}\text { Related } \\
\text { specifi- } \\
\text { cations }\end{array}$ & $\begin{array}{l}\text { Consis- } \\
\text { tency of } \\
\text { the } \\
\text { specifi- } \\
\text { cations } \\
\text { specifications } \\
\text { of a } \\
\text { requirement in } \\
\text { different } \\
\text { models should } \\
\text { be conflicting }\end{array}$ & $\begin{array}{l}\text { Data specification } \\
\text { suggests that Book } \\
\text { Reservation is not } \\
\text { needed but the } \\
\text { functional } \\
\text { requirement } \\
\text { specification } \\
\text { indicates that students } \\
\text { should be able to } \\
\text { reserve books. }\end{array}$ \\
\hline
\end{tabular}

Table 2. Scales for different degrees of rigour

\begin{tabular}{|l|c|}
\hline \multicolumn{1}{|c|}{ Rigour } & Scale \\
\hline Not present & $\mathbf{0}$ \\
\hline Present but weak or not explicit & $\mathbf{1}$ \\
\hline Explicit and rigorous & $\mathbf{2}$ \\
\hline
\end{tabular}

We would also like to stress that it is not enough if a methodology just mentions something like 'Look for missing classes and attributes in this step' or 'Review the class model to identify hidden

attributes'. It does not tell methodology-users much. A good methodology should say, and methodology-users need to know, how to correctly identify and specify all three elements and how to check whether the specification meets the above criteria. It means one not only needs to know 'what to do', but perhaps more importantly, one needs to know 'how to do it'.

Thus, when assessing various methodologies and related techniques, we will try to gauge their rigour using various measurement scales as shown in Table 2. 


\section{Structured Methods}

\section{Method: SSADM Version 4/4+}

Structured System Analysis and Design Method (SSADM) was first launched in 1981, and has been used by UK Governmental Departments ever since. It has gone through many improvements over the years and the major version SSADM Version 4 was launched in 1990. More minor changes were made later and SSADM 4+ was then released in 1996. See [12].

\section{A Summary of Data Requirement Specification Techniques in SSADM}

In SSADM 4 and 4+ the major data analysis model is Logical Data Model (LDM) that includes Logical Data Structure (LDS), otherwise known as Entity Relationship Diagram (ERD). See [2] and [12].

In Step 140 Investigate Current Data, a draft LDM is produced after gathering candidates for entities coming from various sources such as: physical data stores in the current environment, requirement specification, specialist knowledge of the application domain and so on. Together with entities, their main attributes, e.g. key attributes, and some other obvious attributes are discovered. Entity relationships and their degrees are also identified. But there is no urgent need for an entirely valid LDM at this point, since the model will be refined progressively. Towards the end of Step 140, the LDM is revised first by removing redundant relationships such as 'indirect relationships'. Then the LDM is validated against the Data Flow Model (DFM, which consists of Data Flow Diagrams) that is being developed at the same time. For an entity, SSADM requires that, there must be at least one DFD process that creates the entity, at least one process that sets attribute values, and at least one process that deletes the entity. The only exception is a case where given entities are used for references only. The checking is done by drawing up the Process/Entity Matrix. Step 140 concludes with the examination of 'Access Paths' to demonstrate that elementary processes that need to access a number of entities can do so by navigating through the defined relationships.

In Step 320 Develop Required Data Model, the LDM is adjusted according to the user's choice of system functionality. That generally involves removing entities that are not required by the new system and adding new entities that will be required. Entity relationships are then revised and improved in the light of changes in entities. LDM documentation is completed by filling up Entity Description forms, which include information such as names of all known attributes, primary and foreign keys etc... When documenting the entities, cross-references are made to the data stores in the DFM. The Store/Entity Cross-Reference ultimately determines the content of data stores for the DFM.

In Step 330 Derive System Functions, various functions are identified from data flow diagrams, and are documented using Function Definition forms. A function in SSADM is 'a set of processing that users wish to carry out at the same time' [12]. Functions are triggered by events. User interface of each of these functions is defined using I/O Structure diagram(s) that use Jackson Structure Diagram-like notations to 
show detailed exchange of data items between the user and the system. These diagrams are then validated by users.

In Step 340 Enhance Required Data Model, the LDM, which has been developed using a top-down approach, is 'enhanced and confirmed' by Normalised Tables that are developed using the bottom-up Relational Data Analysis (RDA) technique. RDA is performed on some complex I/O (Input/Output) Structures, which were produced as part of Function Definitions. I/O Structures contain rich information about data coming in and going out of the system. Using the RDA technique, the I/O Structures are successively transformed into the Third Normal Form (3NF). After that, 3NF tables are converted into LDS fragments using a mechanistic process that involves four steps. Subsequently, the LDS fragments are compared with the original LDS to resolve differences. When doing so, SSADM suggests that, one should look for a) differences in attributes, such as uncovered attributes, attributes in different entities etc... b) additional entity types and c) additional relationships.

In Step 360 Develop Processing Specification an Entity Access Matrix is developed which demonstrates how events affect entities during their lifetime. These effects are detailed by operations in Entity Life History modelling; they are later incorporated into operations on Effect Correspondence Diagrams. ECDs show how an event affects various entities, and how these entity effects correspond to each other [12].

\section{Assessment}

The main data requirement specification in SSADM is mainly represented by LDM. The LDM is supported by Logical Data Structure, Entity Specifications, Attribute Specifications and Relationship Specifications. Table 3 summarises the assessment of data requirement specification techniques in SSADM.

Table 3. Summary of the assessment of data requirement specification techniques in SSADM

\begin{tabular}{|l|l|c|}
\hline \multicolumn{1}{|c|}{ Criterion } & \multicolumn{1}{|c|}{ How it is met (if at all) } & Rigour \\
\hline $\begin{array}{l}\text { Completeness of } \\
\text { entities }\end{array}$ & $\begin{array}{l}\text { Task 30 of Step 140 Check that the LDM will support } \\
\text { the Elementary Processes from the DFM. } \\
\text { Task 40 of Step 140 Record any new data } \\
\text { requirements or problems with current data in the } \\
\text { Requirements Catalogue: Missing entities can be } \\
\text { uncovered when comparing LDS fragments from } \\
\text { Normalisation with the original LDS. }\end{array}$ & 2 \\
\hline $\begin{array}{l}\text { Completeness of } \\
\text { entity attributes }\end{array}$ & $\begin{array}{l}\text { Task 40 of Step 340 Compare the mini LDM with the } \\
\text { Required System LDM, and resolve any difference: } \\
\text { Comparing fragments of normalised LDS with the } \\
\text { original LDS. Normalisation is performed on I/O } \\
\text { Structures that is a set of data attributes that the users can } \\
\text { provide the system with and expect from the system. }\end{array}$ & 2 \\
\hline $\begin{array}{l}\text { Completeness of } \\
\text { entity relationships }\end{array}$ & $\begin{array}{l}\text { Task 40 of Step 340 Compare the mini LDM with the } \\
\text { Required System LDM, and resolve any difference: } \\
\text { Comparing fragments of normalised LDS with the } \\
\text { original LDS. Normalisation establishes entity } \\
\text { relationships via foreign keys. }\end{array}$ & 2 \\
\hline
\end{tabular}




\begin{tabular}{|c|c|c|}
\hline Criterion & How it is met (if at all) & Rigour \\
\hline $\begin{array}{l}\text { Minimality of } \\
\text { entities }\end{array}$ & $\begin{array}{l}\text { Task } 30 \text { of Step } 140 \text { Check that the LDM will support } \\
\text { the Elementary Processes from the DFM. } \\
\text { Task } 10 \text { of Step } 320 \text {... Exclude elements of the LDM } \\
\text { which are outside the new system... } \\
\text { Task } 10 \text { of Step } 360 \text { Develop the Entity Access Matrix, } \\
\text { and document each event and enquiry in the Event } \\
\text { and Enquiry Catalogue: In Entity Access Matrix } \\
\text { modelling, entities that are affected by no events or too } \\
\text { few events are to be questioned. }\end{array}$ & 2 \\
\hline $\begin{array}{l}\text { Minimality of entity } \\
\text { attributes }\end{array}$ & $\begin{array}{l}\text { Step 340 Enhance Required Data Model: Since RDA } \\
\text { is the analysis of data items in I/O Structures that are } \\
\text { confirmed by the user, certain attributes that were } \\
\text { initially thought to be necessary when in fact they are not, } \\
\text { could be discovered when merging RDA results with the } \\
\text { initial LDS. } \\
\text { Step 360 Develop Processing Specification: Entity Life } \\
\text { History also provides an opportunity to check whether all } \\
\text { attributes are affected by event operations. }\end{array}$ & 2 \\
\hline $\begin{array}{l}\text { Minimality of entity } \\
\text { relationships }\end{array}$ & $\begin{array}{l}\text { Step 340 Enhance Required Data Model: RDA. One } \\
\text { can generally assume that all relationships defined in } \\
\text { RDA in terms of foreign keys are necessary and others } \\
\text { should be examined further. }\end{array}$ & 2 \\
\hline $\begin{array}{l}\text { Correctness of } \\
\text { entities }\end{array}$ & $\begin{array}{l}\text { SSADM provides very detailed documentation standard } \\
\text { for describing entities. User's participation in validating } \\
\text { the documents can be valuable. }\end{array}$ & 1 \\
\hline $\begin{array}{l}\text { Correctness of } \\
\text { entity attributes }\end{array}$ & $\begin{array}{l}\text { Task } 30 \text { of Step } 330 \text { Create I/O Structures or [sic] for } \\
\text { each off-line function. Create I/O Structures for on- } \\
\text { line functions as appropriate. Study more involved } \\
\text { functions using User Interface Design techniques: } \\
\text { User involvement in the development of I/O Structures, } \\
\text { and related User Interface Design Prototyping is } \\
\text { important. }\end{array}$ & 1 \\
\hline $\begin{array}{l}\text { Correctness of } \\
\text { entity relationships }\end{array}$ & $\begin{array}{l}\text { Step } 340 \text { Enhance Required Data Model: RDA. All } \\
\text { entity relationships defined via foreign keys are generally } \\
\text { correct. }\end{array}$ & 1 \\
\hline $\begin{array}{l}\text { Non-redundancy of } \\
\text { entities }\end{array}$ & $\begin{array}{l}\text { Step } 340 \text { Enhance Required Data Model: RDA. } \\
\text { Normalisation necessitate the removal or combination of } \\
\text { entities with similar of same attributes. }\end{array}$ & 2 \\
\hline $\begin{array}{l}\text { Non-redundancy of } \\
\text { entity attributes }\end{array}$ & $\begin{array}{l}\text { Step 340 Enhance Required Data Model: RDA. } \\
\text { Normalisation specifically requires the removal of } \\
\text { derivable attributes etc... }\end{array}$ & 2 \\
\hline $\begin{array}{l}\text { Non-redundancy of } \\
\text { entity relationships }\end{array}$ & $\begin{array}{l}\text { Step } 140 \text { Investigate Current Data: It clearly asks to } \\
\text { remove redundant relationships such as 'indirect } \\
\text { relationships'. } \\
\text { Step } 340 \text { Enhance Required Data Model: RDA. } \\
\text { Relationships derived from the Normalisation are always } \\
\text { optimal. }\end{array}$ & 2 \\
\hline
\end{tabular}




\begin{tabular}{|l|l|c|}
\hline \multicolumn{1}{|c|}{ Criterion } & \multicolumn{1}{|c|}{ How it is met (if at all) } & Rigour \\
\hline $\begin{array}{l}\text { Consistency of the } \\
\text { specifications }\end{array}$ & $\begin{array}{l}\text { There are various stages where cross-checking between } \\
\text { models is done. In Step 140, for instance, one checks } \\
\text { whether all functional requirements can be supported by } \\
\text { the data requirement specification by drawing up a small } \\
\text { Entity/Process Matrix. The comparison of the } \\
\text { Normalisation results with the original LDS is a very } \\
\text { powerful inter-model validation. }\end{array}$ & 2 \\
& Total & 23 \\
\hline
\end{tabular}

\section{Object-Oriented Methods}

\section{Method: The Unified Process}

The Unified Process published in 1999 is a development process model to accompany the Unified Modelling Language. It describes how to make an effective use of the UML models. The Unified Process evolved from the earlier method, the Objectory that later became the Rational Unified Process, and is a product of a collaborative work of three well-known methodologists with contributions from other experts [4].

\section{A Summary of Data Requirement Specification Techniques in the Unified Process}

One of the early activities within the Requirements Workflow involves identification of Domain/Business classes in the form of a Business Model or a Domain Model alongside the Use Case Model and user-interface descriptions [1], [4], and [9]. A Business Model or a Domain Model, which is a less elaborate kind of business model, can be used to establish the system context.

A Domain Model, that basically is a UML class model, shows the most important domain classes together with some obvious attributes and relationships but no or very few operations in the system that are discovered by analysing the requirements specification [4]. Candidates for domain classes are a) Business objects b) Real-world objects and c) Events.

Alternatively, a Business Model can be produced, which encompasses a Business Use Case Model and a Business Class Model. The business use case model details business processes used by business actors. Therefore, use case model of the system will contain a sub-set of business use cases plus some extra use cases if required. The business class model describes the realisation of each of the business use cases. It should be noted that candidates for classes in business class modelling come from the business use case model, while in domain modelling, candidates are derived from the real world. Also, the business class model will have more complete information about the classes, their attributes and operations, since realisation of business use cases have already been demonstrated. A Logical User Interface Design, that shows how 'attributes of the use cases' are utilised by the users, is produced for each use case. The Unified Process suggests looking for information the actors supply to the system and information the actors require from the system etc.

When the Requirements Workflow is completed we will have a tentative class model of the system that is enhanced in the following analysis stage. 
When performing analysis of use case realisation, the Unified Process suggests the use of collaboration diagrams over sequence diagrams [4]. First for each use case, one has to identify participating analysis classes such as boundary classes, control classes and entity classes. Boundary classes deal with the system's interaction with the outside world, and control classes deal with the synchronisation of contributions made by various classes. (In this paper, we will largely concentrate on entity classes). Entity classes handle stored information. These entity classes are discovered using a combination of input from the early business class model, and techniques such as grammatical analysis of use case descriptions and so on.

Identifying Analysis Classes [4] step involves identification of analysis classes together with their responsibilities, attributes, and relationships. The following guidelines are provided (extracted for entity classes only).

- Entity classes are discovered by analysing use-case descriptions, existing domain model etc

After discovering object interactions and class responsibilities, Identifying Attributes step gives us the following guidelines.

- Attribute names are nouns and attribute data types should be conceptual. Try to reuse existing data types.

- Attributes may be separated into classes if there are too many of them.

- Entity class attributes are easy to find. Domain/Business classes provide a good starting point.

- Attributes sometimes need just a definition of them, not the actual attributes, etc...

Identifying Associations and Aggregations requires one to investigate links between objects in collaboration diagrams. These links indicate that the associated classes have a kind of static relationship such as association or aggregations. These relationships 'must exist in response to demands from the various use-case realisations'. So, one should not be concerned with most efficient navigation routes at this stage [4].

Sequence diagrams can be used instead of collaboration diagrams during use case realisation step if one wants to emphasise the timing of messages passed between objects. However, the Unified Process recommends the use sequence diagram in the subsequent design stage. See [4] and also [5].

\section{Assessment}

The principal data requirement specification in the Unified Process is represented by the class model, in particular, by entity classes, their attributes and relationships. The use case model describes the functional requirements of the system and the two models are fed into the use case realisation models. A summary of the assessment of data requirement specification techniques in the Unified Process is shown in Table 4.

Table 4. Summary of the assessment of data requirement specification techniques in the Unified Process

\begin{tabular}{|l|l|c|}
\hline \multicolumn{1}{|c|}{ Criterion } & \multicolumn{1}{c|}{ How it is met (if at all) } & Rigour \\
\hline $\begin{array}{l}\text { Completeness of } \\
\text { classes }\end{array}$ & $\begin{array}{l}\text { Use Case Realisation. When we demonstrate how } \\
\text { various objects contribute to the execution of a use } \\
\text { case, we are bound to discover some missing classes. } \\
\text { But the Unified Process does not say how to discover }\end{array}$ & 1 \\
\hline
\end{tabular}




\begin{tabular}{|c|c|c|}
\hline Criterion & How it is met (if at all) & Rigour \\
\hline & such missing classes. & \\
\hline $\begin{array}{l}\text { Completeness of class } \\
\text { attributes }\end{array}$ & $\begin{array}{l}\text { The Logical User Interface Design. It does present a } \\
\text { chance for users to verify some attributes from classes. } \\
\text { Again it is not explicit. }\end{array}$ & 1 \\
\hline $\begin{array}{l}\text { Completeness of class } \\
\text { relationships }\end{array}$ & $\begin{array}{l}\text { Use Case Realisation. The Unified Process clearly } \\
\text { states that all classes that interact must have a } \\
\text { relationship. }\end{array}$ & 2 \\
\hline Minimality of classes & $\begin{array}{l}\text { Use Case Realisation. The Unified Process states that } \\
\text { 'an entity class that does not participate in any use-case } \\
\text { realisation is unnecessary'. }\end{array}$ & 2 \\
\hline $\begin{array}{l}\text { Minimality of class } \\
\text { attributes }\end{array}$ & $\begin{array}{l}\text { The Logical User Interface Design. It also can be used } \\
\text { to negotiate what information the users do not need } \\
\text { from the system. }\end{array}$ & 1 \\
\hline $\begin{array}{l}\text { Minimality of class } \\
\text { relationships }\end{array}$ & $\begin{array}{l}\text { Use Case Realisation. The Unified Process clearly } \\
\text { states that all classes that interact must have a } \\
\text { relationship. Other relationships are to be questioned. }\end{array}$ & 2 \\
\hline Correctness of classes & $\begin{array}{l}\text { The Logical User Interface Design. The users } \\
\text { involved in the development can indirectly confirm it. }\end{array}$ & 1 \\
\hline $\begin{array}{l}\text { Correctness of class } \\
\text { attributes }\end{array}$ & $\begin{array}{l}\text { The Logical User Interface Design. Users may be able } \\
\text { to verify what these attributes represent by involving in } \\
\text { this process. }\end{array}$ & 1 \\
\hline $\begin{array}{l}\text { Correctness of class } \\
\text { relationships }\end{array}$ & $\begin{array}{l}\text { The Unified Process clearly says when to add a } \\
\text { relationship, but it does not say what kind of } \\
\text { relationship, in terms of cardinality etc, we should add. } \\
\text { So it is not present. }\end{array}$ & 0 \\
\hline $\begin{array}{l}\text { Non-redundancy of } \\
\text { classes }\end{array}$ & $\begin{array}{l}\text { The Unified Process does not say how to identify } \\
\text { semantically redundant classes in the specification. It is } \\
\text { not present either. }\end{array}$ & 0 \\
\hline $\begin{array}{l}\text { Non-redundancy of } \\
\text { class attributes }\end{array}$ & Not present. & 0 \\
\hline $\begin{array}{l}\text { Non-redundancy of } \\
\text { class relationships }\end{array}$ & $\begin{array}{l}\text { The Unified Process also specifically asks for the } \\
\text { removal of class relationships that are solely for easy } \\
\text { navigation. }\end{array}$ & 2 \\
\hline \multirow[t]{2}{*}{$\begin{array}{l}\text { Consistency of the } \\
\text { specifications }\end{array}$} & $\begin{array}{l}\text { In the Unified Process, the use case realisation is the } \\
\text { only major modelling that brings together the use cases } \\
\text { and classes. Other models are a little fragmented. For } \\
\text { instance, Logical User Interface Design is unrelated to } \\
\text { boundary classes. It also mentions use case attributes } \\
\text { but it never suggests where they come from and how } \\
\text { they are connected with attributes of classes. }\end{array}$ & 1 \\
\hline & Total & 14 \\
\hline
\end{tabular}

\section{Summary of Findings}

From the descriptions of each method in the previous two sections, one can see that the way initial LDS and Class Model are produced is very similar. Both methods use a combination of rather informal techniques such as grammatical analysis, investigation of paper documents, consultation with users etc.

When it comes to refinement of the initial model, one can see a gulf of differences. 


\section{How to Identify Classes/Entities and Check Them}

The class modelling in the Unified Process completely relies on a top-down analysis approach. It identifies major classes first, then attributes, followed by relationships.

SSADM, on the other hand, uses a top-down technique to produce an initial Logical Data Model. In addition to that, SSADM also uses a bottom-up technique, RDA. The two techniques in SSADM start from different points, one from the abstract requirements and the other, from concrete information about data in I/O Structures. Then RDA rules are applied to some of the complex I/O Structures, which results in entities whose attributes and relationships are clearly defined. The two Logical Data Structures are then compared to sort out differences.

The Unified Process does not have many checking mechanisms to perform crosschecking between models. Use case realisation is the only major modelling activity that brings together use cases and classes, hence there are some opportunities to reveal missing classes.

SSADM has plenty of steps where the checking is done explicitly and rigorously. For instance, Step 140 clearly states that all entities must be able to support the processing units. That statement is materialised by a small but important matrix, the Entity Process Matrix that summarises how entities are affected by processes.

One can also observe some similarities between SSADM's Effect Correspondence Diagram and Unified Process's Collaboration Diagram. They both show how entities/classes are affected by/contribute to a process/the realisation of a use case. But how do we know which classes/entities contribute to a particular use case/process?

Prior to Effect Correspondence Diagramming in SSADM, one has to produce an Entity Access Matrix that shows which entities are affected by each event. To determine if an event (assuming that an event is a process) affects an entity, one has to see if any instances of entity are created or updated or deleted. One also applies simple rules such as having at least one event to create the entity, another event to modify and yet another one to delete each entity. Only then ECDs are produced. The matrix gives us a good opportunity to check if the specification contains all necessary entities, does not contain extra entities, etc.

The Unified Process attempts to jump straight to show the dynamics of object interactions for each use case without first establishing which and how classes will contribute to various use cases.

Therefore, EAM-like matrix and logical analysis of data items that go in and out of the system are important activities that ensure the data requirement specification in SSADM meet many quality criteria, and such important activities have no counterparts in the Unified Process.

\section{How to Identify Attributes and Check Them}

As far as attributes are concerned, the Unified Process entirely depends on the analyst's insight into the problem. Hardly any concrete guidelines are provided as to how one can identify attributes and validate them.

SSADM also depends on the analyst's insight into the problem at the initial stages. Once the logical user interface (I/O Structures) for the system is designed and agreed by the user, Normalisation is carried out on some complex I/O Structures, resulting in 
LDS fragments that are then compared with the original LDS. There is little room for errors and omissions.

Again, one can see the importance of logical analysis of data items that cross the system's boundaries.

\section{How to Identify Relationships and Check Them}

The Unified Process obviously states that classes that communicate must have a kind of relationship.

SSADM uses Normalisation to validate entity relationships that were created by abstract thinking.

The differences lead us to the following conclusions and recommendations.

\section{Conclusions and Recommendations}

The data requirement specification techniques of SSADM demonstrate a high degree of thoroughness, which in some cases might prove to be a little 'bureaucratic' and over-enthusiastic [3]. But the data requirement specification techniques of the Unified Process lack a kind of rigour that one can find in SSADM. In particular, there are not many crosschecks between models. We believe that this can be rectified as follows.

1. Generally models like I/O Structures are very important. Because, if and only if we can establish what information users want from the system (outputs) and what they can provide to the system (inputs), we can have a reliable basis from which we can derive important attributes of entity classes (and classes themselves in some situations). We are also of opinion that there is a scope in the Unified Process to incorporate I/O Structure-like diagrams to Logical User Interface Designs of use cases or more specifically boundary classes ${ }^{1}$. The primary focus of the diagrams will be in describing data attributes coming in and going out of the system in a logical way. SSADM uses Relational Data Analysis technique to group these data items. One may also use a similar, but less formal, technique, such as a simple mapping technique, to ensure that entity classes can support the attributes specified in the boundary classes.

2. I/O Structure-like diagrams can also be useful when looking for classes that contribute to a use case realisation. It means that if data items defined in an I/O Structure-like diagram match attributes of certain classes, these classes would somehow have to contribute to the use case realisation.

3. Finally, we believe that a tool such as Entity Access Matrix is required to describe clearly which classes contribute to which use cases. See Fig.1. Such matrix gives us an overall picture of various classes' participation in use cases and the matrix can be used to detect invalid classes and use cases as one can do in SSADM.

\footnotetext{
${ }^{1}$ In this paper, we did not discuss Boundary Class in length. The Unified Process does mention that boundary classes should be used to capture incoming and outgoing data items, rather than getting overwhelmed with GUI objects. But the Unified Process treats boundary classes as rather informal, in a sense that information from these classes are never used by models. Therefore, we would like to promote importance of these boundary classes by using systematic ways to capture information and utilise them appropriately.
} 


\begin{tabular}{|l|c|c|c|c|}
\cline { 2 - 5 } \multicolumn{1}{c|}{} & Class 1 & Class 2 & Class ... & Class N \\
\hline Use Case 1 & $\mathrm{X}$ & $\mathrm{X}$ & & \\
\hline Use Case 2 & & $\mathrm{X}$ & $\ldots$ & \\
\hline Use Case $\ldots$ & $\mathrm{X}$ & & $\ldots$ & \\
\hline Use Case $\mathrm{N}$ & & & & \\
\hline
\end{tabular}

Fig. 1. An EAM-like matrix to show allocation of classes to use cases

\section{Future Work}

We are also investigating some other popular object-oriented methods such as OMT, in order to critically assess the rigour of their data requirement specification techniques using the same criteria proposed in this paper. Further to the third conclusion, our next research will concentrate on a comparison and evaluation of requirement specification techniques concerning system functionality used by Structured and Object-oriented methods.

\section{References}

1. Booch G., Rumbaugh J., and Jacobson I. (1999) The Unified Modeling Language User Guide, Addison Wesley Longman, Massachusetts

2. Goodland M. and Slater C. (1995) SSADM Version 4: A Practical Approach. McGraw-Hill Europe, Berkshire, England

3. Hares, J. S. (1994) SSADM version 4: The Advanced Practitioner's Guide, John Wiley \& Sons Ltd, West Sussex, England

4. Jacobson I., Booch G., Rumbaugh J. (1999) The Unified Software Development Process: The complete guide to the Unified Process from the original designers, Addison Wesley

5. Jacobson I., Christerson M., Jonsson P., Overgaard G. (1992) Object-oriented Software Engineering: A use case driven approach, Addison-Wesley Longman, Essex, England

6. Kotonya G. and Sommerville I. (1998) Requirements Engineering: process and techniques, John Wiley \& Sons, West Sussex, England

7. Loucopoulos P. \& Karakostas V. (1995) System Requirements Engineering, McGraw-Hill

8. Pfleeger S. L. (1998) Software Engineering: Theory and practice, Prentice Hall

9. Rumbaugh J., Jacobson I., and Booch G. (1999) The Unified Modeling Language Reference Manual, Addison-Wesley

10. Sommerville I.(1995) Software Engineering (Fifth Edition), Addison Wesley Longman

11. Vliet J. C. van (1993) Software Engineering: Principles and Practice (July 1997 reprint), John Wiley \& Sons, West Sussex, England

12. Weaver P. L., Lambrou N. and Walkley M. (1998) Practical SSADM 4+: A complete tutorial guide (second edition), Financial Times Professional Limited (Pitman Publishing) 